\title{
Arterial hypertension as a factor in the choice of conflict resolution strategies by elderly persons
}

\author{
NATALIA TIKHONOVA ${ }^{1, A-E}$, NINA DEMINA ${ }^{1,2, A-F}$, LUDMILA KLIMATCKAIA ${ }^{3, A, E}$, \\ ALEKSANDER OSIPOV ${ }^{1,4, A-F}$, MIKHAIL KUDRYAVTSEV ${ }^{3-5, A-F}$, TATYANA ZHAVNER ${ }^{4,8-E}$, \\ ANDREI SHPAKOU ${ }^{6, A, D-F}$ \\ ORCID iD: 0000-0003-4340-5211
}

${ }^{1}$ Krasnoyarsk State Medical University named after professor V.F. Voyno-Yasenetsky, Russia

${ }^{2}$ Krasnoyarsk State Agrarian University, Russia

${ }^{3}$ Krasnoyarsk State Pedagogical University named after V.P. Astafyev, Russia

${ }^{4}$ Siberian Federal University, Krasnoyarsk, Russia

${ }^{5}$ Reshetnev Siberian State University of Science and Technology, Krasnoyarsk, Russia

${ }^{6}$ Yanka Kupala State University of Grodno, Belarus

A - Study Design, B - Data Collection, C - Statistical Analysis, D - Data Interpretation, E - Manuscript Preparation, F - Literature Search, G - Funds Collection

Summary Background. Interpersonal conflicts are one of the causes of depressive syndromes among patients, which contribute to the development of arterial hypertension. Minimizing the risk of conflicts between elderly patients is necessary for providing effective therapy.

Objectives. To identify and analyze the behavioral patterns of elderly people in conflict situations suffering from and not suffering from hypertension.

Material and methods. The number of patients of the gerontological center who took part in the research amounted to 117 females (55+ years of age). The studies of the Thomas-Kilmann Instrument (TKI) conflict assessment methodology were used to identify the characteristics of the behavior of elderly patients in conflict situations.

Results. The largest number of patients was identified as the leading conflict resolution strategy in both groups. We agree that a significant number of those studied could not decide on the leading strategy of behavior in the conflict and use two or more strategies to resolve conflict situations. Patients with hypertension have higher rates of resistance to conflict than those who do not have this disease. Conclusions. The strategy of adaptation is the leading strategy for resolving conflict situations among elderly people who have and have not been diagnosed with hypertension. This is why it was revealed that elderly people with hypertension have higher levels of resistance to conflict.

Key words: geriatrics, hypertension, conflict (psychology), aged.

Tikhonova N, Demina N, Klimatckaia L, Osipov A, Kudryavtsev M, Zhavner T, Shpakou A. Arterial hypertension as a factor in the choice of conflict resolution strategies by elderly persons. Fam Med Prim Care Rev 2018; 20(4): 368-372, doi: https://doi.org/10.5114/ fmpcr.2018.79349.

\section{Background}

Elderly people are the fastest growing group of the population in the modern world. Hypertension is one of the most common diseases in the elderly [1]. The distribution of hypertension of elderly patients has been recorded by health professionals over the last 30 years of observations [2]. According to medical observations, it is revealed that $67 \%$ of elderly people who are over 60 years old have this diagnosis in the US. Moreover, the percentage of people suffering from hypertension increases significantly with the age of the patients [3]. It was also found that hypertension is more common among older females than among older males [4]. It is known that this disease requires constant monitoring and strict adherence to medically prescribed medications to reduce the risk of cardiovascular [5] and renal disease [6]. Besides this, health professionals emphasize the need to find effective strategies for the treatment and care of elderly patients with hypertension $[7,8]$. The need for quality treatment is due to the connection between the problems of physical and mental health of elderly people [9-11]. Moreover, health professionals believe that the treatment and care for el- derly patients with mental health problems (depression states) and those suffering from cardiovascular diseases is extremely complicated $[12,13]$. Of course, understanding and managing the physical and mental functioning of these elderly people will help to increase the duration [14] and the quality of their life [15].

Experts note that the problems of developing hypertension are quite relevant in the elderly in the countries of the former Soviet Union [16]. A large part of the elderly live temporarily or permanently in gerontological centers in Russia. Scientists believe that communal living of a large number of people suffering from various diseases, including hypertension, often leads to different conflicts between the elderly. It is known that interpersonal conflicts are the most common types of chronic stress [17], which in its turn leads to the development of hypertensive diseases $[18,19]$. Scientists believe that stress is an important factor in the development of hypertension due to the fact that the heart rate is significantly increased under stress conditions [20]. Eventually, various stress and depression states are barriers to the treatment of hypertension in patients of varying gender and age [21]. Meanwhile, it has also been revealed 
that a patient's knowledge of the presence of hypertension is a significant factor in increasing the risk of various mental and depressive disorders [22]. Furthermore, the need to take into account the psychological characteristics of the patients is an urgent task in gerontological centers under these conditions. The specialists note the influence of the psychological self-regulation on the level of the physical and functional state of the elderly people [23-25]. As a result, recent studies suggest a more detailed study of the role and influence of various psychosocial factors on the development of hypertension in patients of varying gender and age, including elderly people [26]. Thanks to health professionals, "schools for hypertensive patients" are conducted. Their goal is to minimize the risk of developing high blood pressure and its adverse effects. However, in the study of hypertension, a number of side-effects were identified: the development of dementia, the risk of disability, mental disorders and depression states [27]. In case a detailed study of these risks and the search for optimal strategies for the treatment of elderly patients with the hypertension are found improvement in the quality of care for elderly is necessary. It was revealed that the symptoms of depression are closely related to hypertension. Stress and depression are an accelerating factoring in the development of hypertension, and hypertension can worsen the symptoms of depression. It should also be noted that the use of certain antihypertensive drugs has a number of side effects that contribute to the development of mental disorders and depression states [28]. In view of this, health professionals and psychologists point out the need for serious research into the relationship of hypertension and psychiatric disorders of elderly patients [29]. Considering that mental disorders and depression are frequent causes of interpersonal conflicts, the authors of the article decided to study the behavior of elderly people in more detail, with hypertension in conflict situations.

\section{Objectives}

To identify and analyze the behavioral patterns of elderly people in conflict situations suffering from and not suffering from hypertension.

\section{Material and methods}

\section{Study location and respondents}

To begin with, these studies were approved by the local ethics committee of the Krasnoyarsk State Medical University, named after Professor V.F. Voyno-Yasenetsky. It was revealed that the studies were conducted in the gerontological center in Krasnoyarsk in Russia. In connection with the above, the authors of the article determined that the number of the patients of the center who took part in the research amounted to 117 females. The age of the patients studied was from 55 to 85 years of age.

\section{Data collection instruments and operational definitions}

The patients were divided into two groups. Group $1(n=59)$ included patients who did not suffer from hypertension, and group $2(n=58)$ included patients with this disease.

The studies of the Thomas-Kilmann Instrument (TKI) conflict assessment methodology were used to identify the characteristics of the behavior of elderly patients in conflict situations. Besides this, a scale of the assessment of popular exit strategies from conflicts was used to assess the results of the questionnaire proposed by K. Thomas and R. Kilmann. Owing to the level of the psychological resistance of the patients to the emergence of conflict situations was determined using the methodology - the express diagnostics of the resistance to the conflicts [30]. This method was developed by Russian psychologists and rec- ommended by the Ministry of Education of the Russian Federation for study at universities by students studying psychology.

\section{Statistical analysis}

Moreover, the determination of the reliability of the differences of results of the survey and questioning of the patients was carried out with the help of the Mann-Whitney U-test.

\section{Results}

\section{Priority strategies for conflict resolution of patients with and without hypertension}

It was possible to identify the following preferences of elderly people in resolving conflict situations during the questioning and testing of the patients. As a result of the above, it is indicated that in both groups of patients, the strategy of adapting to a conflict situation is the preferred way to resolve conflicts. In group 1, 25.01\% of the respondents emphasized the priority of choosing this strategy, and in group $2-27.85 \%$. Furthermore, in the groups, the preferences in conflict resolution strategies differ. The second choice in the list of strategies in group 1 was avoiding conflict situations. Accordingly, the second option in group 2 was the strategy of searching for compromise solutions. The third option in group 1 was the strategy of cooperation in resolving conflict situations. In group 2, this was the strategy of avoiding the conflicts. The fourth choice in group 1 was the strategy of finding compromise solutions. In the group of elderly people suffering from hypertension, the fourth option was the strategy of cooperation in resolving conflict situations. Lastly, in both groups of patients, the strategy of rivalry in conflict resolution was seen. Accordingly, it should be noted that more than a quarter of the patients under study in both groups (Group 1 - 24.73\% and Group 2 - 26.58\%) use two or more strategies for resolving conflict situations. Hence, the general data of the patients' preferred strategies for action in conflict situations is presented in Table 1.

Table 1. The general data of the patient's' preferred strategies for action in conflict situations

\begin{tabular}{|l|l|l|}
\hline Position & Group №1 $(\boldsymbol{n}=\mathbf{5 9 )}$ & Group №2 $(\boldsymbol{n}=\mathbf{5 8})$ \\
\hline 1 & adaptation $-25.01 \%$ & adaptation $-27.85 \% *$ \\
\hline 2 & avoidance $-17.07 \%$ & compromise $-18.99 \%$ \\
\hline 3 & cooperation $-13.17 \%$ & avoidance $-15.19 \%$ \\
\hline 4 & compromise $-9.78 \%$ & cooperation $-6.33 \%$ \\
\hline 5 & rivalry $-9.74 \% *$ & rivalry $-5.06 \%$ \\
\hline
\end{tabular}

$* p<0.01-$ reliability of differences of the results.

As a matter of fact, the results show that the majority of the interviewed patients both with the hypertension and without this disease prefer to adapt the strategy of partial infringement of their own interests in favor of the interests of the conflicting party. A significant difference in percentages among the elderly was found $(p<0.01)$. At the same time the strategy of adaptation to the conflict was in favor of patients suffering from hypertension.

\section{Patient preferences}

In addition, a fairly large proportion of the elderly interviewed prefer to use two or more behavior strategies to resolve conflict situations in both groups. However, in the group of patients suffering from hypertension, the percentage of people choosing two or more exit strategies is significantly $(p<0.01)$ higher $(26.58 \%)$ than in the group without this disease 
(24.73\%). Elderly people diagnosed with hypertension are much more likely (almost 2 times more) to use the strategy of finding compromise solutions in conflicts than elderly patients who do not have this diagnosis.

Elderly people without hypertension often use the strategy to avoid direct conflict situations. It should be noted that both groups of patients do not use the conflict resolution strategy sufficiently. At the same time, the advantage was found in patients in group 1 more than 2 times.

The strategy of rivalry in a conflict was chosen by a minority of the patients in both groups, but the percentage of patients giving priority to this strategy is higher $(p<0.01)$ in group 1.

\section{Level of psychological resistance of patients to conflicts}

Furthermore, an assessment of the level of conflict-resistant patients showed that elderly people with hypertension has a level of psychological resistance to various conflict situations which is significantly $(p<0.01)$ higher than elderly people without this disease. A high level of resistance was detected in $46.42 \%$ of the patients in group 2 . With this in mind, the majority of the patients in group $1(48.34 \%)$ have an average level of psychological resistance to conflicts. These estimates are presented in Table 2.

\begin{tabular}{|c|c|c|c|}
\hline \multirow[t]{2}{*}{ Patients } & \multicolumn{3}{|c|}{ Level of stability } \\
\hline & High & Medium & Low \\
\hline Group №1 $(n=59)$ & $37.58 \%$ & $48.34 \% *$ & $14.08 \% *$ \\
\hline Group №2 $(n=58)$ & $46.42 \% *$ & $43.54 \%$ & $10.04 \%$ \\
\hline
\end{tabular}

$* p<0.01-$ reliability of differences of the results.

\section{Discussion}

The causes of the onset and development of arterial hypertension of elderly people are different. The risk factors for the development of this disease are: age of patients, race [31], presence of diabetes, obesity and a number of other diseases [32]. We believe that an important role in the development of this disease affects the socio-economic status of the patients. It was found that elderly people with a higher socio-economic status (a high level of education and income) monitor and treat hypertension more successfully $[4,33]$. However, in the authors' studies, this factor did not play a significant role, since all studied patients were in the same situation: the place of residence, food, medical preparations, etc. One of the main reasons for the development of hypertension in elderly people is the presence of depressive syndromes arising through interpersonal social conflicts [34]. It was revealed that patients with depression, which occurred during the development of various diseases, including hypertension, are subjected to strong emotional stress and are less inclined to solve problems of overcoming psychological stresses [35]. It is evident that people diagnosed with hypertension have an increased risk of the various psychological stresses $[36,37]$. However, in some studies, there is evidence that there is no direct relationship between the presence of psychological stress and an increase in systolic blood pressure in elderly males diagnosed with hypertension [38]. It is known that females have a higher risk of developing hypertension than males $[1,4]$. The research data of the authors of the article shows that the studied patients - females diagnosed with hypertension - have higher rates of resistance to stress (internal interpersonal conflicts) than older women without this diagnosis. This is quite interesting. Since hypertension is inextricably linked to depression and other negative psychological reactions [39], one could expect the opposite result when testing the patients. There is evidence that the presence of chronic diseases in old age contributes to the emergence of depressive syndromes in patients, which contributes to the development of hypertension [35]. However, the results of these studies can be explained by the rich life experience of the studied patients with hypertension. Experts believe that elderly people, through accumulated life experience, are able to adapt to emerging social conflicts better and use more effective strategies for their resolution compared to young people [17]. It can also be assumed that elderly people with hypertension consciously avoid conflict situations, because they feel a relationship between the level of psycho-emotional state and the value of blood pressure. The level of psychological well-being has an impact on the risk of the developing hypertension, which was confirmed by scientific studies [40,41]. Health professionals confirm a significant cross-correlation between hypertension and depressive disorders [20]. Consequently, a higher level of psychological resistance to the various conflict situations of elderly women with hypertension can be explained by a direct relationship between the state of health of these patients in stressful conflict situations and a calm state. Of course, the fact that people with hypertension are much less exposed to strong emotions than those who do not suffer from this disease confirm the scientific studies [42].

\section{Limitations of the study}

In the analysis of the results, it is necessary to take into account the significant difference in the age of the patients (from 55 to 85 years). Perhaps these age differences could have some impact on the results of the study. It should also be noted that the majority of patients, in addition to hypertension, had other diseases: diabetes, various stages of obesity and other diseases. The presence of a number of chronic diseases in the elderly will undoubtedly have some impact on the level of psychological resistance to conflict in elderly people.

\section{Conclusions}

Elderly patients with hypertension had higher levels of resistance to conflict situations. Most likely, this study opens up significant opportunities for the further study of the reasons for choosing the certain strategies of behavior in conflict situations for elderly people - the patients of gerontological centers. To summarize, a further study of the relationship between various diseases and the psychological characteristics of elderly patients will help to realize the concept "ProLongaVita" and improve the quality of life of elderly people.

Source of funding: This work was funded by the authors' own resources.

Conflicts of interest: The authors declare no conflicts of interest.

\section{References}

1. Eshkoor S, Hamid T, Shahar S, et al. Factors affecting hypertension among the Malaysian elderly. J Cardiovasc Dev Dis 2016; 3: 8, doi:10.3390/jcdd3010008.

2. Robles NR, Macias JF. Hypertension in the elderly. Cardiovasc Hematol Agents Med Chem 2015; 12(3): 136-145. 
3. Aprahamian I, Sassaki E, dos Santos M, et al. Hypertension and frailty in older adults. J Clinic Hypertens 2018; 20(1): 186-192. https:// doi.org/10.1111/jch.13135.

4. Van Rossum K, Van de Mheen H, Witteman J, et al. Prevalence, treatment, and control of hypertension by sociodemographic factors among the Dutch elderly. Hypertens 2000; 35: 814-821.

5. Gerasimov SN, Posnenkova OM, Kiselev AR, et al. Characteristics of patients with arterial hypertension influencing to the achievement of target pressure: data of polyclinics of the working village. Sib Med Rev 2017; 2: 97-103 (in Russian).

6. Lionakis N, Mendrinos D, Sanidas E, et al. Hypertension in the elderly. World J Cardiol 2012; 4(5): 135-147, doi:10.4330/wjc.v4.i5.135.

7. Buford TW. Hypertension and aging. Ageing Res Rev 2016; 26: 96-111, doi: 10.1016/j.arr.2016.01.007.

8. Jardim L, Jardim T, de Souza W, et al. Multiprofessional treatment of high blood pressure in very elderly patients. Arg Bras Cardiol 2017; 108(1): 53-59, doi:10.5935/abc.20160196.

9. Sidik SM, Rampal L, Afifi M. Physical and mental problems of the elderly in a rural community of Sepang, Selangor. Malays J Med Sci 2004; 11(1): 52-59.

10. Mann SJ. Psychosomatic research in hypertension: the lack of impact of decades of research and new directions to consider. $J$ Clinic Hypertens 2012; 14(10): 657-664, doi: https://doi.org/10.1111/j.1751-7176.2012.00686.x

11. Esmayel EM, Eldarawy MM, Hassan MM, et al. Mental health problems and sociodemographic correlates in elderly medical inpatients in a university hospital in Egypt. Curr Gerontol Geriatr Res 2013; 2013: 923710, doi: 10.1155/2013/923710.

12. Jiang W. Depression and cardiovascular disorders in the elderly. Psychiatr Clin North Am 2018; 41(1): 29-37, doi: 10.1016/j. psc.2017.10.003.

13. Wolińska W, Pawlak IE, Mroczek B. Coexistence of insomnia and chronic diseases in over 60 years olds. Fam Med Prim Care Rev 2016; 18(3): 364-367, doi: 10.5114/fmpcr/63896.

14. Park JY, Chiu W, Won D. Sustainability of exercise behavior in seniors: an application of the extended theory of planned behavior. J Phys Educ Sport 2017; 17(1): 342-347, doi: 10.7752/jpes.2017.01050.

15. Doro MR, Nascimento-Carvalho B, Ruaro M, et al. Higher levels of physical activity reduce spending on medicines in the elderly. $J$ Phys Educ Sport 2018; 18(1): 157-162, doi: 10.7752/jpes.2018.01020.

16. Footman K, Roberts B, Tumanov S, et al. The comorbidity of hypertension and psychological distress: a study of nine countries in the former Soviet Union. J Public Health 2013; 35(4): 548-557, doi: 10.1093/pubmed/fdt019.

17. Sneed RS, Cohen S. Negative social interactions and incident hypertension among older adults. Health Psychol 2014; 33(6): 554-565, doi: 10.1037/hea0000057.

18. Orlov AV, Rotar OP, Boyarinova MA, et al. Anxiety-depressive disorders - connecting link between social-economic, behavioral and biological cardiovascular risk factors? Sib Med Rev 2017; 2: 60-66 (in Russian).

19. Hu B, Liu X, Yin S, et al. Effects of psychological stress on hypertension in middle-aged Chinese: a cross-sectional study. PLOS ONE 2015; 10(6): e0129163, doi: https://doi.org/10.1371/journal.pone.0129163.

20. Mushtaq N, Najam N. Depression, anxiety, stress and demographic determinants of hypertension disease. Pac J Med Sci 2014; 30(6): 1293-1298, doi: 10.12669/pjms.306.5433.

21. Khatib R, Schwalm JD, Yusuf S, et al. Patient and healthcare provider barriers to hypertension awareness, treatment and follow up: a systematic review and meta-analysis of qualitative and quantitative studies. PLOS ONE 2014; 9(1): e84238, doi: 10.1371/journal. pone.0084238.

22. Pickering T. Now we are sick: labeling and hypertension. J Clin Hypertens (Greenwich) 2006: 8(1): 57-60.

23. Kozina Z, lermakov S, Bartik P, et al. Influence of self - regulation psychological and physical means on aged people's functional state. J Hum Sport Exerc 2018; 13(1): 99-115, doi: 10.14198/jhse.2018.131.10.

24. Riegel B, Moser DK, Buck HG, et al. Self care for the prevention and management of cardiovascular disease and stroke. JAHA 2017; 6(9): e006997, doi: https://doi.org/10.1161/JAHA.117.006997.

25. Pour Heidari Roudberi AM, Manzhulovskyy VM. Rationale of physical rehabilitation of patients with violation coronary circulation. Pedagog Psychol Med Biol Probl Phys Educ Sport 2013; 17(9): 80-84, doi: 10.6084/m9.figshare.751561.

26. Cuffee Y, Ogedegbe C, Williams NJ, et al. Psychosocial risk factors for hypertension: an update of the literature. Curr Hypertens Rep 2014; 16(10): 483, doi: 10.1007/s11906-014-0483-3.

27. Buford TW. Hypertension and aging. Ageing Res Rev 2016; 26: 96-111, doi: 10.1016/j.arr.2016.01.007.

28. Ma L, Tang Z, Sun F, et al. Risk factors for depression among elderly subjects with hypertension living at home in China. Int J Clin Exp Med 2015; 8(2): 2923-2928.

29. Grimsrud A, Stein DJ, Seedat S, et al. The association between hypertension and depression and anxiety disorders: results from a nationally-representative sample of South African adults. PLoS ONE 2009; 4(5): e5552, doi: https://doi.org/10.1371/journal.pone.0005552.

30. Fetiskin NP, Kozlov VV, Manulov GM. Rapid diagnosis of resistance to conflict. In: Fetiskin NP, Kozlov VV, Manulov GM. (eds). Sociopsychological diagnostics of personality development and small groups. Moscow: Publishing house of the Institute of Psychotherapy; 2002: 490 (in Russian).

31. Ostchega Y, Dillon C, Hughes G, et al. Trends in hypertension prevalence, awareness, treatment, and control in older U.S. adults: data from the national health and nutrition examination survey 1988 to 2004. J Am Geriatr Soc 2007; 55(7): 1056-1065.

32. Ribeiro B, dos Santos Neto P, Nascimento J, et al. Hierarchical analysis of hypertension with the polymorphic variant of the ACE gene and other risk factors in the elderly. Int J Cardiovasc Sci 2017; 30(1): 52-60, doi: 10.5935/2359-4802.20170031.

33. Ahn S, Lee Smith M, Cho J, et al. Hypertension awareness and associated factors among older Chinese adults. Front Public Health 2013; 1: 67, doi: 10.3389/fpubh.2013.00067.

34. Shah MT, Zonderman AB, Waldstein SR. Sex and age differences in the relation of depressive symptoms with blood pressure. Am J Hypertens 2013; 26(12): 1413-1420, doi: 10.1093/ajh/hpt135.

35. Singh D, Kedare J. A study of depression in medically ill elderly patients with respect to coping strategies and spirituality as a way of coping. J Geriatr Mental Health 2014; 1(2): 83-89, doi: 10.4103/2348-9995.152427.

36. Hamer M, Batty D, Stamatakis E, et al. Hypertension awareness and psychological distress. Hypertension 2010; 56(3): 547-550, doi: https://doi.org/10.1161/HYPERTENSIONAHA.110.153775.

37. Ojike $N$, Sowers JR, Seixas A, et al. Psychological distress and hypertension: results from the national health interview survey for 2004-2013. Cardiorenal Med 2016; 6(3): 198-208, doi: 10.1159/000443933.

38. Ringoir L, Pedersen S, Widdershoven J, et al. Prevalence of psychological distress in elderly hypertension patients in primary care. Neth Heart J 2014; 22(2): 71-76, doi:10.1007/s12471-013-0502-z.

39. Wenxin XU, Menglong LI, Jiwei YAO. Intervention of collective exercise on the mental health of elderly hypertension patients. Iran J Public Health 2016; 45(3): 314-321.

40. Trudel-Fitzgerald C, Boehm JK, Kivimaki M, et al. Taking the tension out of hypertension: a prospective study of psychological well being and hypertension. J Hypertens 2014; 32(6): 1222-1228, doi: 10.1097/HJH.0000000000000175. 
41. Cuevas AG, Williams DR, Albert MA. Psychological factors and hypertension: a review of the literature. Cardiol Clin 2017; 35(2): 223-230, doi: 10.1016/j.ccl.2016.12.004.

42. Kantariya A, Desai M. Emotional intelligence in patients with high blood pressure and heart disease. Int J Indian Psychol 2016; 4(1): 20-24.

Tables: 2

Figures: 0

References: 42

Received: 20.06.2018

Reviewed: 21.06.2018

Accepted: 24.06 .2018

Address for correspondence:

Andrei Shpakou, MD, PhD, Assoc. Prof.

Department of Sports Medicine and Rehabilitation

Yanka Kupala State University of Grodno

22, Ozeshko

Grodno 230023

Belarus

Tel.: +375(29)78310343

E-mail: shpakofff@tut.by 